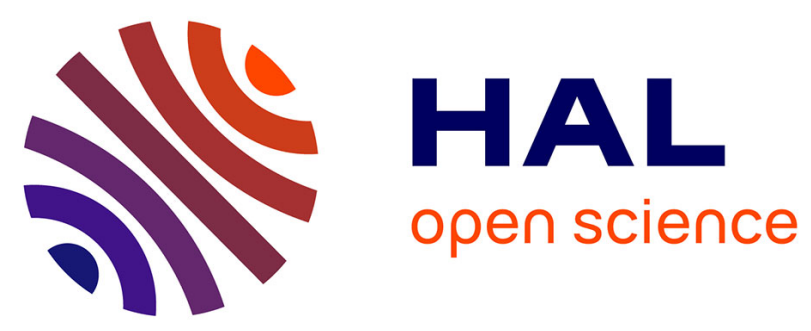

\title{
Decreased respiratory-related postural perturbations at the cervical level under cognitive load
}

\author{
Louis Clavel, Valérie Attali, Isabelle Rivals, Marie-Cécile Nierat, Pierantonio
}

Laveneziana, Philippe Rouch, Thomas Similowski, Baptiste Sandoz

\section{To cite this version:}

Louis Clavel, Valérie Attali, Isabelle Rivals, Marie-Cécile Nierat, Pierantonio Laveneziana, et al.. Decreased respiratory-related postural perturbations at the cervical level under cognitive load. European Journal of Applied Physiology, 2020, 120 (5), pp.1063-1074. 10.1007/s00421-020-04345-1 . hal-02591203

\section{HAL Id: hal-02591203 \\ https://hal.science/hal-02591203}

Submitted on 15 May 2020

HAL is a multi-disciplinary open access archive for the deposit and dissemination of scientific research documents, whether they are published or not. The documents may come from teaching and research institutions in France or abroad, or from public or private research centers.
L'archive ouverte pluridisciplinaire HAL, est destinée au dépôt et à la diffusion de documents scientifiques de niveau recherche, publiés ou non, émanant des établissements d'enseignement et de recherche français ou étrangers, des laboratoires publics ou privés. 


\title{
Decreased respiratory-related postural perturbations at the cervical level under cognitive load
}

\author{
Louis Clavel ${ }^{1,2}$ (1) $\cdot$ Valérie Attali ${ }^{1,2,3} \cdot$ Isabelle Rivals $^{1,4} \cdot$ Marie-Cécile Niérat $^{1} \cdot$ Pierantonio Laveneziana $^{1,5}$. \\ Philippe Rouch $^{2} \cdot$ Thomas Similowski $^{1,6} \cdot$ Baptiste Sandoz $^{2}$
}

\begin{abstract}
Purpose In healthy humans, postural and respiratory dynamics are intimately linked and a breathing-related postural perturbation is evident in joint kinematics. A cognitive dual-task paradigm that is known to induce both postural and ventilatory disturbances can be used to modulate this multijoint posturo-ventilatory (PV) interaction, particularly in the cervical spine, which supports the head. The objective of this study was to assess this modulation.

Methods With the use of optoelectronic sensors, the breathing profile, articular joint motions of the cervical spine, hip, knees and ankles, and centre of pressure (CoP) displacement were measured in 20 healthy subjects (37 years old [29; 49], 10 females) during natural breathing (NB), a cognitive dual task (COG), and eyes-closed and increased-tidal-volume conditions. The PV interaction in the CoP and joint motions were evaluated by calculating the respiratory emergence (REm).

Results Only the COG condition induced a decrease in the cervical REm (NB: 17.2\% [7.8; 37.2]; COG: 4.2\% [1.8; 10.0] $p=0.0020$ ) concurrent with no changes in the cervical motion. The CoP REm (NB: 6.2\% [3.8; 10.3]; COG: 12.9\% [5.8; 20.7] $p=0.0696$ ) and breathing frequency (NB: 16.6 min-1 [13.3; 18.7]; COG: 18.6 min-1 [16.3; 19.4] $p=0.0731)$ tended to increase, while the $\mathrm{CoP}(p=0.0072)$ and lower joint motion displacements $(p<0.05)$ increased.

Conclusion This study shows stable cervical spine motion during a cognitive dual task, as well as increased postural perturbations globally and in other joints. The concurrent reduction in the PV interaction at the cervical spine suggests that this "stabilization strategy" is centrally controlled and is achieved by a reduction in the breathing-related postural perturbations at this level. Whether this strategy is a goal for maintaining balance remains to be studied.
\end{abstract}

Keywords Breathing $\cdot$ Centre of pressure $\cdot$ Cognitive dual task $\cdot$ Joint kinematics $\cdot$ Postural control $\cdot$ Optoelectronic plethysmography · Posturo-ventilatory interaction · Cervical spine

\section{Abbreviations}

Amp Signal amplitude

AP Antero-posterior

BF Breathing frequency

Communicated by Lori Ann Vallis.

Louis Clavel

clavel.louis@gmail.com

1 UMRS1158 Neurophysiologie Respiratoire Expérimentale et Clinique, Sorbonne Université, INSERM, 75005 Paris, France

2 Arts et Metiers Institute of Technology, IBHGC, 151 bd de l'Hopital, 75013 Paris, France

3 Service des Pathologies du Sommeil (Département R3S), AP-HP, Groupe Hospitalier Universitaire APHP-Sorbonne Université, Site Pitié-Salpêtrière, 75013 Paris, France
BMI Body mass index

CI Confidence interval

COG Cognitive dual-task condition

CoM Centre of mass

$\mathrm{CoP} \quad$ Centre of pressure

CW Chest wall volume
4 Equipe de Statistique Appliquée, ESPCI Paris, PSL Research University, 75005 Paris, France

5 Service des Explorations Fonctionnelles de la Respiration, de l'Exercice et de la Dyspnée, Département "R3S", Assistance Publique des Hôpitaux de Paris, Groupe Hospitalier Pitié-Salpêtrière Charles Foix, 75013 Paris, France

6 Service de Pneumologie, Médecine Intensive et Réanimation (Département R3S), AP-HP, Groupe Hospitalier Universitaire APHP-Sorbonne Université, Site Pitié-Salpêtrière, 75013 Paris, France 


$\begin{array}{ll}\text { EC } & \text { Eyes-closed condition } \\ \text { ITV } & \text { Increased tidal volume condition } \\ \text { ML } & \text { Medio-lateral } \\ \text { NB } & \text { Natural breathing condition } \\ \text { PV } & \text { Posturo-ventilatory } \\ \text { Q1; Q3 } & \text { First quartile; third quartile } \\ \text { REm } & \text { Respiratory emergence } \\ \text { TE } & \text { Expiratory time } \\ \text { TI } & \text { Inspiratory time } \\ \text { TLA } & \text { Time-locked averaging }\end{array}$

\section{Introduction}

Postural and respiratory dynamics are intimately linked and exhibit strong temporal relationships in healthy humans (Dally 1908; Gurfinkel et al. 1971; Perry and Carrier 2006). Ribcage movements during breathing disturb an individual's balance by modifying the costo-vertebral articulation position, thoracic spinal curvature and postural alignment (Dally 1908; Attali et al. 2019) and by inducing ribcagerelated centre of mass (CoM) displacements. Breathingrelated postural perturbations during natural breathing are partially counteracted by phasic contractions of paravertebral (Kantor et al. 2001) and pelvic floor muscles (Hodges et al. 2007; Talasz et al. 2011). The interaction between the breathing-related postural perturbations and these counteracting muscle contractions that occurs to maintain balance is defined as the posturo-ventilatory (PV) interaction. From a stabilometric point of view, the PV interaction is characterized by minimal rhythmic displacements of the centre of pressure (CoP-the whole body $\mathrm{CoM}$ vertical projection on the ground) induced by natural breathing at rest, whereas this displacement almost disappears during apnoea (Kantor et al. 2001; Caron et al. 2004) and increases with CO2induced hyperventilation (David et al. 2012) or voluntary deep breathing (Hamaoui et al. 2010). The PV interaction is centrally integrated (Gurfinkel et al. 1971), as evidenced by the perturbations that occur in patients with stroke (Manor et al. 2012) or by the anticipated increases-i.e., those involving cortical resources-in the role of the diaphragm in postural control during rapid postural adjustments (Hodges et al. 1997).

The PV interaction acts on a multijoint kinetic chain with several degrees of freedom at the spine, hip, knee and ankle levels (Gurfinkel et al. 1971; Hodges et al. 2002) to control breathing-related postural instability (Kuznetsov and Riley 2012). Compared to other joints in the postural chain, the cervical spine directly supports the head and is highly involved in the regulation of its position in space. It plays a crucial role in the maintenance of balance, as suggested by its role in sit-to-stand tasks (Hamaoui and Alamini-Rodrigues 2017) and by the presence of impaired stabilometric parameters in patients with a history of moderate neck trauma (Gandelman-Marton et al. 2016) or neck pain (Quek et al. 2018). In addition, changing the orientation of the head during tracking requires a synergy between the most inferior joints and the cervical spine for an individual to maintain balance (Park et al. 2012). Permanent adjustments of the cervical curvature during standing are needed to preserve an adequate head-to-pelvis alignment, which is essential for balance (Vital and Senegas 1986; Dubousset 1994; Amabile et al. 2018), as well as to maintain the head position and a horizontal gaze (Hasegawa et al. 2017), which are important for the transmission of the appropriate visual, vestibular and neck proprioceptive afferent feedback signals (Bove et al. 2009; Williams et al. 2017; Malmström et al. 2017). These adjustments of the cervical curvature are anticipated during tasks requiring attention, such as complex visual (Boulanger et al. 2017) or motor tasks (Hamaoui and Alamini-Rodrigues 2017), as evidenced by prefrontal cortex recruitment, which indicates their central nature (Jahn et al. 2004; Taube et al. 2008; Mihara et al. 2008). Therefore, even though it is a part of the postural chain involved in the PV interaction, the cervical spine is centrally modulated by predominant "nonrespiratory" cortical adjustments, which may compete with the central control of the PV interaction. Indeed, compared to other joints in the postural chain, the cervical spine exhibits less breathing-related mobility during natural breathing (Hodges et al. 2002; Kuznetsov and Riley 2012) and higher variability when the breathing amplitude increases (Kuznetsov and Riley 2012).

The dual-task paradigm is known to divert cortical resources and induce an increase in cognitive load (Stelzel et al. 2018), and it has been validated for the investigation of the interactions between cognitive processes and other cortical functions such as postural control (Huxhold et al. 2006; Lacour et al. 2008; Stelzel et al. 2018) and the cortical control of breathing (Mador and Tobin 1991; Grassmann et al. 2016). Cognitive load is indeed known to be independently associated with modulations in postural control (Huxhold et al. 2006; Lacour et al. 2008; Stelzel et al. 2018) and breathing patterns (Mador and Tobin 1991; Grassmann et al. 2016). To date, no specific modulations in the PV interaction under a cognitive load have been described; one study reported reduced postural sway, which was partly related to a reduction in breathing amplitude, in young adults (Hagio et al. 2018). This result suggests that central postural perturbations induced by a cognitive task may be compensated by a reduction in breathing-related postural perturbations, indicating a strong interaction between cognition and the $\mathrm{PV}$ interaction.

Therefore, we hypothesized that cognitive processes can modulate the PV interaction and its distribution along the multijoint postural chain, with less important breathing-related postural perturbations occurring at 
the cervical level compared to other joints. To test these hypotheses, we used a cognitive dual-task methodology, and we assessed the global effect of the PV interaction on CoP displacement, as well as on the joint motions in the postural chain, with a focus on the cervical spine. The $\mathrm{PV}$ interaction is a delicate phenomenon that is easily altered, and the choice of our cognitive task was driven by the necessity to prevent the occurrence of any respiratory changes or postural perturbations linked to the cognitive task itself, particularly at the cervical level. Hence, motor tasks such as eye tracking (which induces head movements) and vocal counting (which involves the respiratory system) were not appropriate. Therefore, purely mental tasks were chosen, while the recall task (to verify that the subjects had truly completed the mental task) was performed only when the registration ended. Both cognitive tasks that were used in this study tested working memory, and one task additionally tested the subject's calculation ability and attentional capacities.

\section{Materials and methods}

\section{Subjects}

Twenty-one healthy adult subjects (age $\geq 18$ years) were included in the study (10 F, age: 37 years [29; 49], BMI: $22.9 \mathrm{~kg} / \mathrm{m}^{2}$ [20.6; 25.5], data presented as the median [Q1; Q3]). None of the subjects had a history of postural or respiratory disease, and all subjects had normal pulmonary function test results. This study was approved by the ethics committee Ile-de-France VI (Paris, France) (CPP IDF VI 06036) and recorded in the ISRCTN registry under the number ISRCTN56129394. All subjects gave their written consent to participate.

\section{Protocol}

A total of 65 retroreflective markers were placed on the subjects; four were placed on the head, 41 were placed on the trunk, seven were placed on each leg, and three were placed on each foot (Fig. 1a). Motion data were captured with an optoelectronic system (Vicon Nexus 1.8.5, Oxford, UK) using 12 cameras (Vero $1 \mathrm{MPa}$ ) that were placed around the subject and a sampling rate of $100 \mathrm{~Hz}$ (Fig. 1c); the motion data were used to determine the breathing profile and joint motions (cervical spine, hips, knees and ankles). One force plate (BP 4051040-2 k, AMTI, Watertown, USA) measuring the subject's CoP displacements was synchronized with the optoelectronic system at the same sampling frequency. The motion and CoP displacement data were simultaneously recorded with Nexus software.
The subjects were instructed to stand relaxed and barefoot on the force plate with the feet located shoulder-width apart and the arms placed alongside the body. The first set of several 45-s recordings was taken randomly under four different conditions: (1) a natural breathing reference condition (NB); two cognitive dual-task conditions (COG), which consisted of (2) listening and remembering 8 words, then repeating them once the previous task was completed (COG1) and (3) listening to five multiplication problems, performing them mentally, then giving the answers once the registration had ended (COG2); and (4) an eyes-closed condition (EC). During these conditions, no specific instructions were given regarding breathing. An additional thirty-second recording was performed under an increased voluntary tidal volume (ITV) condition, during which the subjects were asked to increase their tidal volume but not their breathing frequency. For all conditions except for EC, the subjects were instructed to focus on a landmark on the wall to maintain horizontal gaze.

\section{Signal processing}

\section{CoP displacements}

Subject-specific antero-posterior (AP) and medio-lateral (ML) axes were defined from the four foot markers (Fig. 1b). The AP axis was defined as the line joining the middle of the anterior markers and the middle of the posterior markers projected in the horizontal plane. The ML axis was defined as the line perpendicular to the AP axis in the horizontal plane. The output of the force plate allowed the computation of the CoP time series in the AP direction. The amplitude (Amp) of the CoP displacements was estimated by the mean of their linear envelopes.

\section{Breathing profile}

From the 41 markers placed on the trunk, the chest wall (CW) volume was computed at each time point as the volume enclosed in the surface of the triangular mesh delimited by the spatial marker locations (Fig. 1a), following the method developed in 1996 by Cala et al. (1996) using GreenOstogradski's theorem. In the following equation, $S$ is the surface, $V$ is the volume enclosed by $S_{i}, F_{i}$ is an arbitrary vector considered as the unit vector $(F), n_{i}$ is the normal unit vector at the different points of $S_{i}$, and $\nabla$ is the divergence operator, which is considered the unit divergence. The analytical expression of the theorem becomes:

$$
\int_{S} \vec{F} \cdot \overrightarrow{n_{i}} d S_{i}=\int_{V} \nabla \vec{F} d V_{i}=\int_{V} d V_{i}
$$



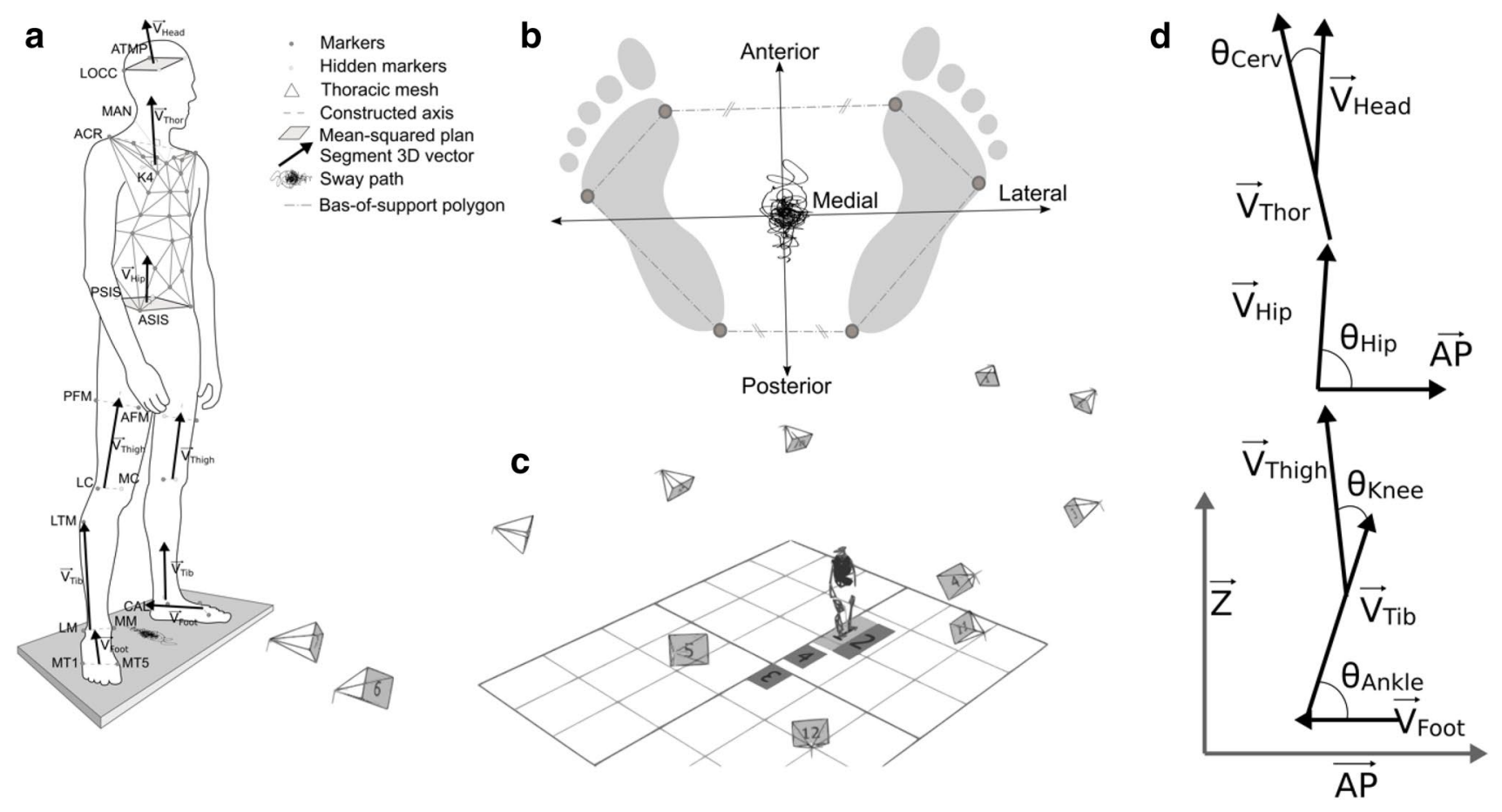

Fig. 1 a Locations of the retroreflective markers and thoracic mesh used to define the body segment frame; $\mathbf{b}$ definitions of a specific subject's antero-posterior and medio-lateral axes according to the foot markers; c positions of the cameras located around the subject; d segment vector projected in the sagittal plane and the definition of the articular joint angle (ATMP anterior temple bone, LOCC lateral occipital bone, MAN manubrium, $A C R$ acromion, $K 4$ fourth kyphosis

In the discrete form, the $\mathrm{CW}$ volume can be computed by summing the areas of the regions in the $\mathrm{K}$ triangle constituting the chest wall mesh, with $A_{i}$ corresponding to the area of each region:

$C W=\sum_{i=i}^{K} \vec{F} \cdot \vec{n}_{i} \cdot A_{i}$

With the signal of the variation in the $\mathrm{CW}$ volume, the start of each inspiration and expiration event was located. The inspiration/expiration events were defined as the local maxima and minima obtained from the volume signal: the end of an inspiration event corresponded to a local maximum, and the end of an expiration event corresponded to a local minimum. A respiratory cycle was defined as the duration between the start of two successive inspiration events. The global breathing frequency (BF) was calculated as the ratio between the number of respiratory cycle integers $\left(n_{\mathrm{C}}\right)$ and the elapsed time (i.e., $45 \mathrm{~s}$ ). The mean inspiratory (TI) and expiratory (TE) times were computed over the whole breathing period. The amplitude (Amp.) of variation in the $\mathrm{CW}$ volume was estimated in litres by the mean of its linear envelopes. vertebra, ASIS/PSIS anterior/posterior superior iliac spine, $A F M / P F M$ anterior/posterior femoral marker, $L C / M C$ the most lateral/medial point on the border of lateral tibial condyle, LTM lateral tibial marker, $L M / M M$ tip of the lateral/medial malleolus, CAL calcaneus, MT1/ $M T 5$ first/fifth metatarsal bone, $\theta$ angle computed for each joint; $A P$ antero-posterior axis, $Z$ vertical axis)

\section{Joint motions}

Seven specific 3D vectors were considered in a subjectspecific frame $\left(F_{\text {sub }}\right)$ and defined with in the AP, ML and vertical axes. The head $\left(V_{\text {Head }}\right)$, thoracic $\left(V_{\text {Thor }}\right)$, hip $\left(V_{\text {Hip }}\right)$, thigh $\left(V_{\text {Thigh }}\right)$, tibial $\left(V_{\text {Tib }}\right)$ and foot frames $\left(V_{\text {Foot }}\right)$ were then defined using the local segment markers. $V_{\text {Head }}$ and $V_{\text {Hip }}$ were defined as the normal of the mean-squared plane defined by the four markers on each segment. $V_{\text {Thor }}$ was defined as the cross product of the vectors defined; the vector between the right and left acromion markers and the vector defined by the K4-manubrium markers were calculated first, then $V_{\text {Thor }}$ was calculated as the cross product of them (more simply, $V_{\text {Thor }}$ is orthogonal to the two other vectors defined by the acromion marker on one side and the $\mathrm{K} 4$ and manubrium markers on another side). $V_{\text {Thigh }}, V_{\text {Tib }}$ and $V_{\text {Foot }}$ were defined by the markers located on the proximal and distal parts of each segment. These seven vectors were then projected in the sagittal plane (defined by the AP and $Z$ axes), and the motions at the four joint levels (cervical spine, hip, knee and ankle) were computed as the angles between the projected vectors (Fig. 1d). Cervical spine motion was computed as the angle between $V_{\text {Head }}$ and $V_{\text {Thor }}$, pelvic motion 
was computed as the angle between $V_{\text {Hip }}$ and the AP axis, knee motion was computed as the angle between $V_{\text {Thigh }}$ and $V_{\text {Tib }}$ and ankle motion was computed as the angle between $F_{\text {Tib }}$ and $F_{\text {Foot }}$. The amplitudes (Amps) of the joint motions (cervical spine, hip, knee and ankle angles) were estimated by the means of their linear envelopes.

For each kinematic signal, the power spectral density was computed from the signal, which was downsampled to $10 \mathrm{~Hz}$, using Welch's periodogram over 512 points with a 128-point Hamming window and 66-point overlap (1 point every $0.0196 \mathrm{~Hz}$ ).

\section{Posturo-ventilatory interaction}

The posturo-ventilatory interaction was estimated by respiratory emergence (REm) (Hamaoui et al. 2010) and by timelocked averaging (TLA) (Kuznetsov and Riley 2012) variables, which both require a calculation using the respiratory signal and synchronized motion signal as follows. The REm is a measure of the weight of the respiratory component during movement and was assessed following a method that was previously described (Hamaoui et al. 2010). In brief, fast Fourier transformation was performed on the motion signal, the REm was computed in the frequency domain as the ratio of the average power of a band of $0.08 \mathrm{~Hz}$ centred on the mean breathing frequency and the overall average power of the motion signal. A REm close to $100 \%$ indicates that the respiratory component is a major component of the motion signal. In this study, the REm was assessed in the $\mathrm{CoP}$ displacement projected on the AP axis and cervical spine, hip, knee and ankle motions in the sagittal plane. For the TLA, each breathing cycle was resampled to obtain
100 equally spaced points. Changes in the signals were then computed over the duration of each breathing cycle as the deviation in a signal from the value at the beginning of the cycle (Fig. 2). For the four joint angles (cervical spine, hip, knee and ankle), the presence of significant movements repeated throughout the breathing cycle was determined following a method that was previously described (Kuznetsov and Riley 2012): first, the 95\% confidence interval (95\% CI) over the breathing cycle (step 1 to 100) was computed; then, a movement was considered significant if for over $20 \%$ of the breathing cycle, the value 0 was not included in the $95 \%$ CI. Significant movements with a 95\% CI entirely less than 0 were considered flexion movements, and those entirely greater than 0 were considered extension movements (Fig. 3).

\section{Data analysis}

For the knees and ankles, the Amp, TLA and REm values were averaged across the left and right sides. The results for the COG1 and COG2 conditions were also averaged (COG). The majority of the variables were non-normally distributed (Shapiro-Wilk test), and all of them are described by the median and interquartile range [Q1; Q3]. The continuous variables were compared with Wilcoxon's test, and the proportions were compared with Fisher's exact test on the $2 \times 2$ corresponding contingency tables, considering a significance level of 0.05 . The change in PV interaction along the multijoint postural chain with a cognitive load was assessed by comparing the REm values derived from the CoP displacement and cervical spine, hip, knee and ankle motions and the occurrences of changes in the TLA (flexion, extension or no
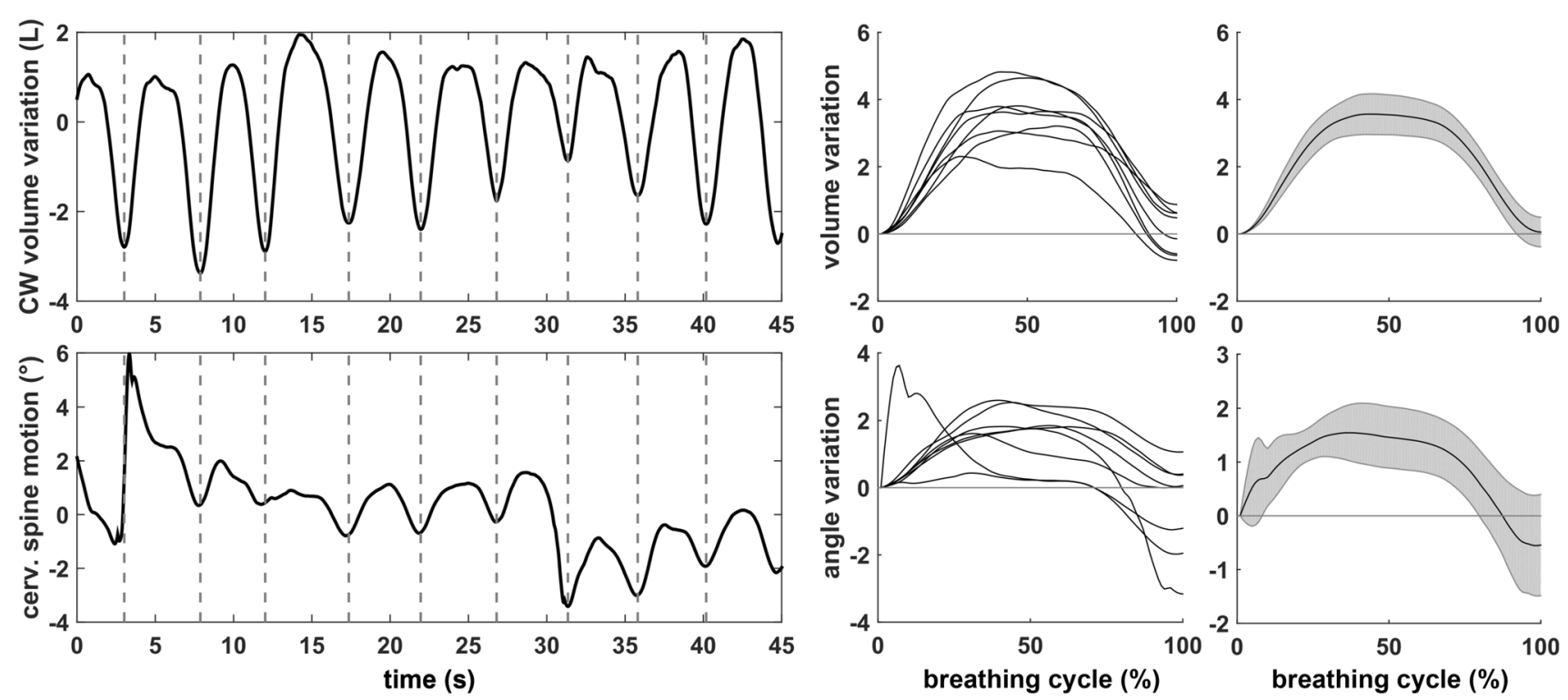

Fig. 2 Left: beginning of each cycle (-); middle: the variation in each signal; right: 95\% confidence interval for the signal variations 

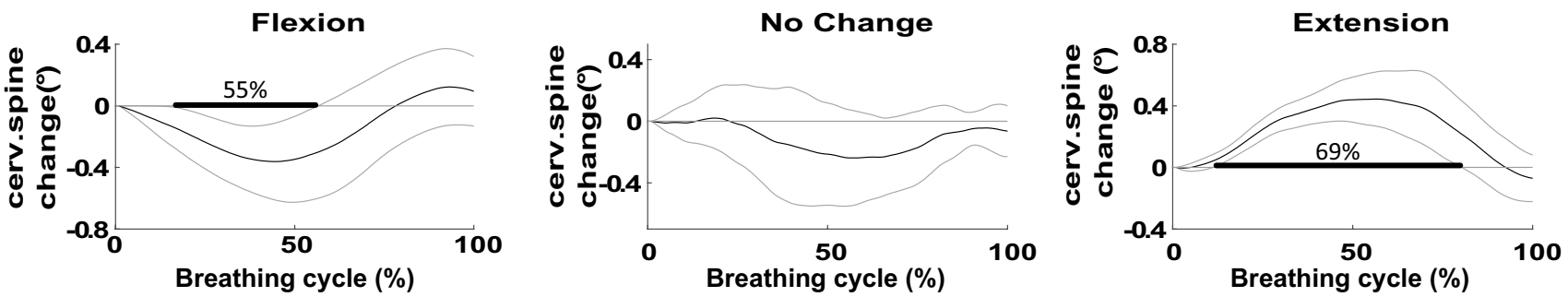

Fig. 3 Representative cervical spine changes over a breathing cycle with respect to the beginning of each cycle for three subjects under different conditions, with the mean value shown as the black line and the $95 \%$ confidence interval (CI) shown as the grey shaded

region. Left: flexion with the CI entirely less than zero over $55 \%$ of the breathing cycle; centre: no significant change with a CI including zero over the entire breathing cycle; right: extension with the $\mathrm{CI}$ entirely greater than zero over $69 \%$ of the breathing cycle

change) for the four joint motions (cervical spine, hip, knee and ankle) between the COG and NB conditions (analysis 1). The change in PV interaction induced by a cognitive load at the cervical level was compared to the change induced by the EC and ITV conditions and was assessed by the REm derived from the cervical spine motion (analysis 2). Figure 4 summarizes the different computed variables and performed analyses in a flowchart.

\section{Results}

Data from one subject were excluded due to data recording issues, as two pelvic markers were missing. The data from twenty subjects were included in the analysis. The subjects' baseline characteristics are presented in Table 1.

\section{Modulation of the PV interaction along the multijoint postural chain during a cognitive load (analysis 1 )}

For COG1 and COG2, 7/8 words $[6 ; 8]$ and $4 / 5$ multiplication answers [3; 5], respectively, were recalled by subjects. During the COG condition, compared to the NB condition, the BF tended to increase $(+1.5$ min- $1[-0.6 ; 4.6]$, $p=0.0731)$, the TE decreased $(-0.09 \mathrm{~s}[-0.29 ; 0.09]$, $p=0.0228)$, TI $(-0.03 \mathrm{~s}[-0.24 ; 0.19], p=0.2959)$ and $\mathrm{CW}$ volume variation $(-0.05 \mathrm{~L}[-0.97 ; 042], p=0.3905)$ remained unchanged. The COG condition was associated with an increase in the CoP Amp by $+2.2 \mathrm{~mm}[0.2$; 6.3] $(p=0.0072)$. The amplitude of cervical motion was unchanged $\left(+0.02^{\circ}[-0.49 ; 0.73], p=0.2180\right)$, while significant increases in the amplitudes of motion were observed for the knee $+0.08^{\circ}[0.02 ; 0.57](p=0.0072)$ and

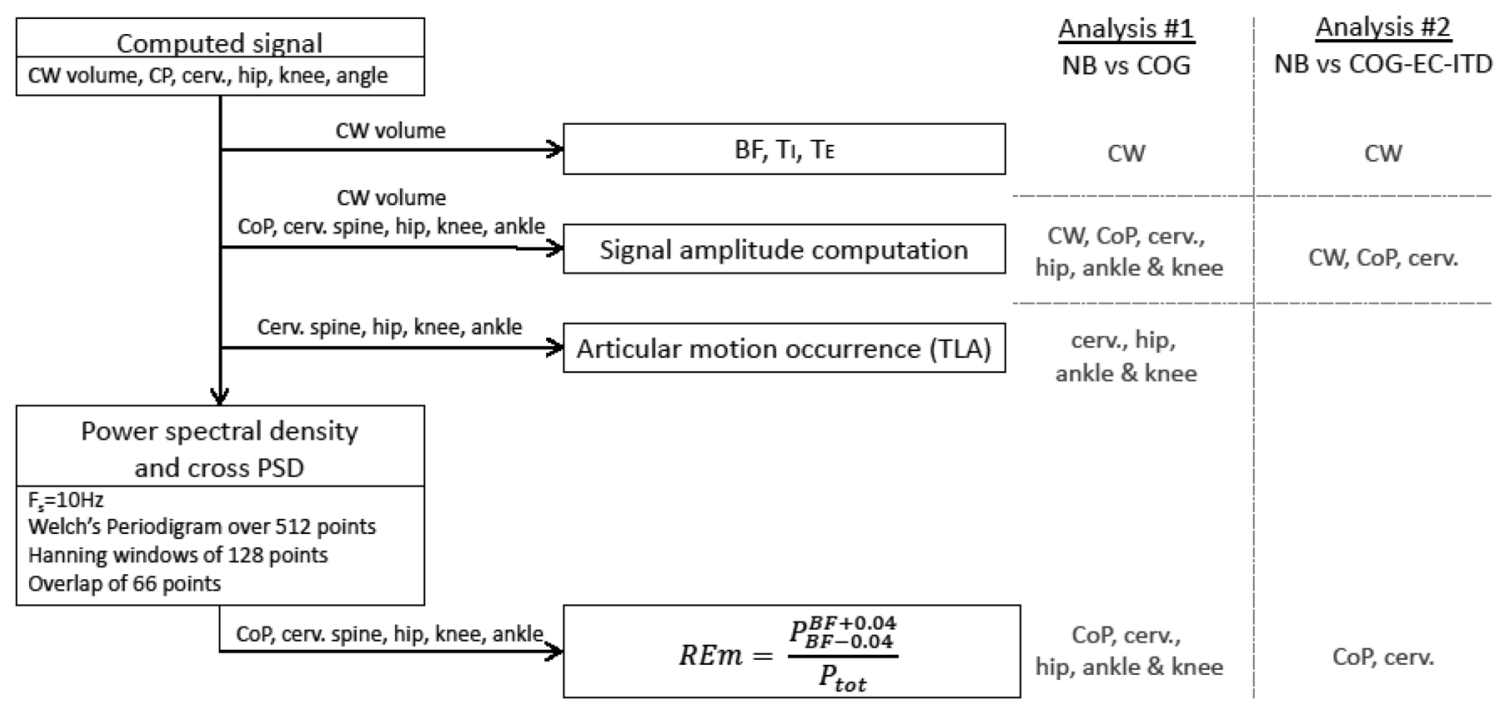

Fig. 4 Flowchart presenting the computation of each studied variable and its use in analyses 1 and 2. ( $C W$ volume chest wall volume, $C o P$ centre of pressure, cerv. spine cervical spine, $P S D$ power spec- tral density, $R E m$ respiratory emergence, $B F$ breathing frequency, $T I$ inspiratory time, $T E$ expiratory time, $N B$ natural breathing, $C O G$ cognitive tasks, $E C$ eyes closed, ITV increased tidal volume) 
Table 1 Anthropomorphic characteristics and pulmonary function testing results

\begin{tabular}{ll}
\hline Sex $(\mathrm{M} / \mathrm{F})$ & $10 / 10$ \\
Age $($ years $)$ & $39[29 ; 50]$ \\
Height $(\mathrm{cm})$ & $171[163 ; 175]$ \\
Weight $(\mathrm{kg})$ & $69[56 ; 78]$ \\
BMI $\left(\mathrm{kg} / \mathrm{m}^{2}\right)$ & $23.2[20.5 ; 25.6]$ \\
SVC $(\%$ predicted $)$ & $114[106 ; 124]$ \\
FRC $(\%$ predicted $)$ & $105[96 ; 116]$ \\
TLC $(\%$ predicted $)$ & $109[99 ; 117]$ \\
RV $(\%$ predicted $)$ & $90[82 ; 103]$ \\
FEV & $(\%$ predicted $)$ \\
\hline
\end{tabular}

The results are presented as the median [Q1; Q3]

$S V C$ slow vital capacity, FRC functional residual capacity measured by helium dilution, TLC total lung capacity, $R V$ residual volume, $F E V_{l}$ forced expiratory volume in one second

ankle $+0.12^{\circ}[0.03 ; 0.60](p=0.0152)($ Fig. 5). Regarding the PV interaction, the REm increased nonsignificantly for the $\operatorname{CoP}(p=0.0696)$ but significantly decreased at the cervical level $(p=0.002)$, and it remained unchanged at the other joints (Fig. 6). The TLA analysis showed a significant decrease in the occurrence of breathing articular motion at the cervical spine and ankle levels but no change at the knee and hip levels. This phenomenon is illustrated in one subject (Fig. 7a), showing that the breathing-related perturbation manifested predominantly by the extension of the cervical spine, which was observed during the NB condition and was counteracted during the COG condition. At the cervical level, breathing-related extension and flexion movements were reduced globally by a similar magnitude; however, different profiles of cervical motion were observed between subjects (Fig. 7b; Table 2). Table 2 presents changes in the PV interaction between the NB and COG conditions for the REm and TLA analyses.

\section{Cervical PV interaction variations by conditions (analysis 2)}

With respect to the NB condition, only the COG condition induced a decrease in the breathing-related postural perturbation at the cervical level, as evidenced by a significant reduction in the $\operatorname{REm}(p=0.002)$ (Table 3). Moreover, only the COG condition altered the ventilatory profile, as evidenced by a decrease in the TE and an increase in the $\mathrm{BF}$ (ns), while no change was observed under the ITV and EC conditions (Table 3 ). The amplitude of the CoP displacement increased during the COG and ITV conditions and remained unchanged during the EC condition. The motion of the cervical spine remained unchanged during the COG condition, while it decreased during the EC condition and increased during the ITV condition (Table 3).

\section{Discussion}

This study shows that a cognitive load induces specific changes in the PV interaction, as attested by a change in the breathing-related postural perturbation along the postural chain, with a reduction at the cervical level only. This result
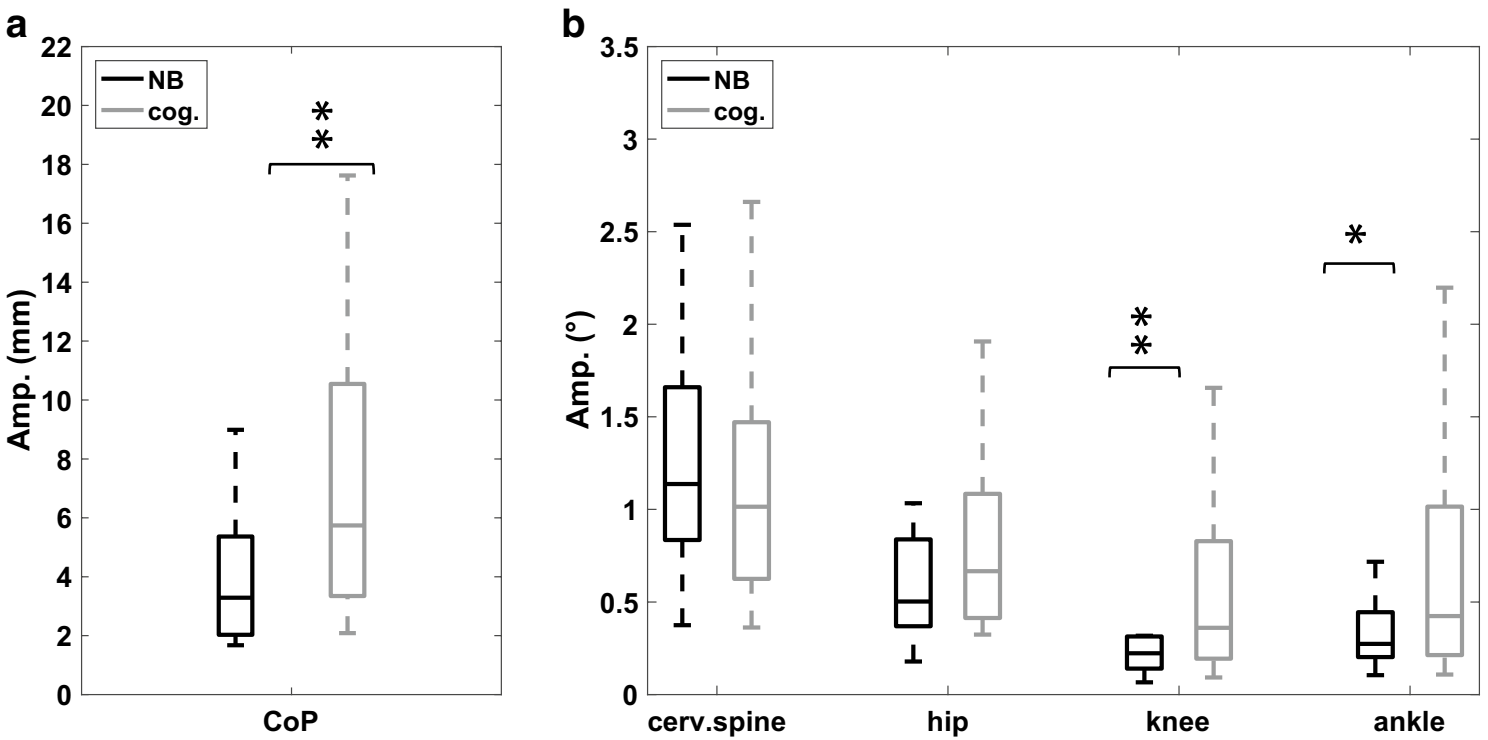

Fig. 5 Variations in the amplitude (Amp.) of a the centre of pressure (CoP) displacement; $\mathbf{b}$ joint rotations (cervical spine, hip, knee, ankle) during the natural breathing (NB) and cognitive conditions (COG) in the standing position in $N=20$ subjects. $(* p<0.05 ; * * p<0.01 ; * * * p<0.001)$ 


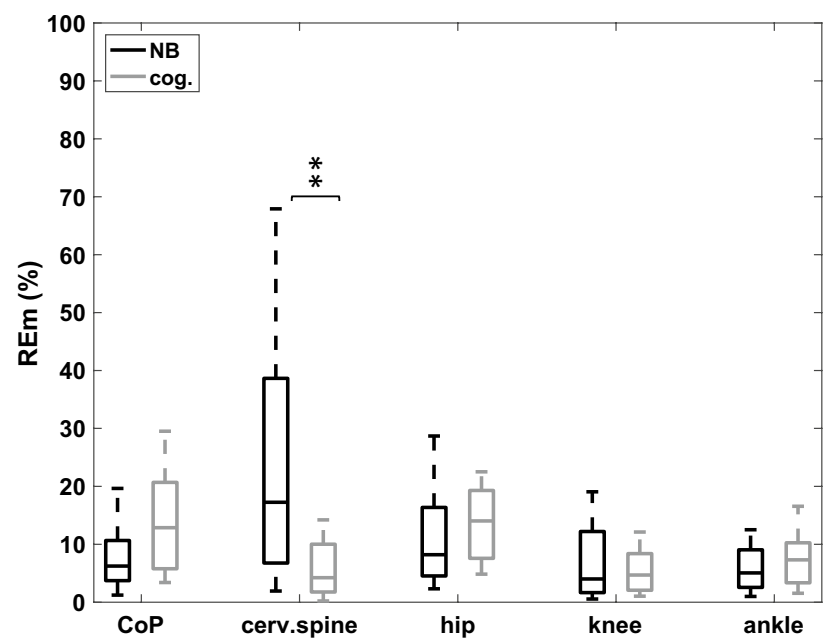

Fig. 6 Variations in respiratory emergence (REm) for the centre of pressure $(\mathrm{CoP})$ displacement amplitude and joint motions (cervical spine, hip, knee, ankle) during the natural breathing (NB) and cognitive conditions (COG) in the standing position in $N=20$ subjects. (Wilcoxon's test: $* p<0.05 ; * * p<0.01 ; * * * p<0.001$ )

was concurrent with an increase in global postural perturbations and lower limb motions, while the cervical motion remained unchanged. This result suggests that the reduction in the ventilatory-related perturbation at the cervical level protects the cervical spine from the postural perturbation induced by the cognitive load.

\section{Posturo-ventilatory interaction and cognition}

Cognitive dual-task paradigms allow us to investigate interactions between cognitive processes and other cortical functions, such as postural control (Huxhold et al. 2006; Lacour et al. 2008) or the cortical control of breathing (Grassmann et al. 2016). A cognitive load is known to perturb the control of balance by diverting attentional resources (Huxhold et al. 2006; Lacour et al. 2008). These interactions between the mental process and postural control are mostly modulated by visual or motor stimuli, the difficulty of the cognitive task, postural constraints, sensorimotor expertise (for example, in experts in gymnastics), and ageing (Huxhold et al. 2006). The subjects in our study were all healthy and had no sensorimotor expertise. They were in a relaxed standing position without any postural stimulation, and the orientation of their gaze was constant across the conditions. Therefore, we may anticipate that the postural impact of a cognitive task on individuals' balance depends mostly on their age and on the intensity of the cognitive load (Huxhold et al. 2006; Lacour et al. 2008). A cognitive load is generally associated with improved balance parameters in subjects in their twenties (Huxhold et al. 2006; Hagio et al. 2018), with no change or impaired balance in older subjects (Lacour et al. 2008), and/ or during a high cognitive load (Huxhold et al. 2006; Lacour et al. 2008). As expected, considering the median age of the subjects in this study (39 years) and the high cognitive load to which they were subjected, we observed impaired balance during the COG condition. We observed a relative
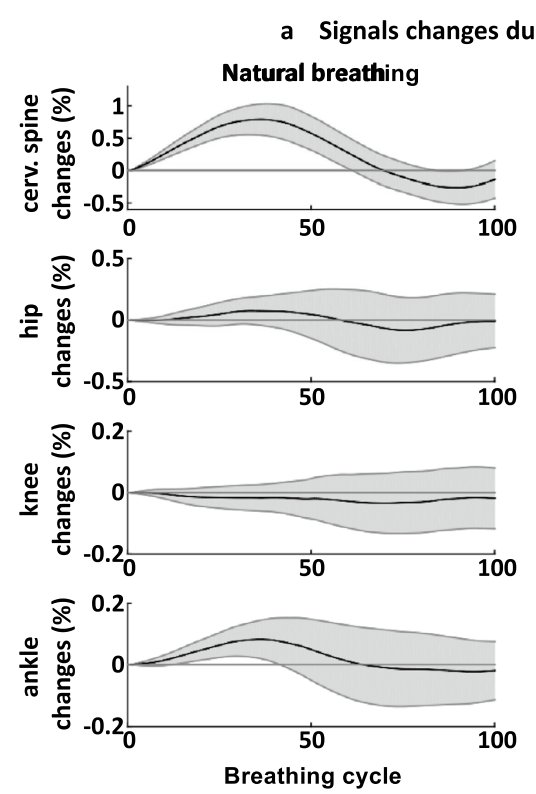
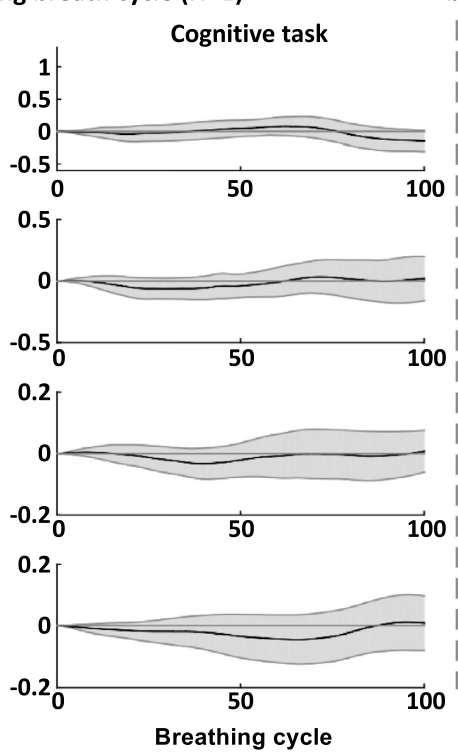

b Articulation motion occurrences $(\mathrm{N}=\mathbf{2 0})$

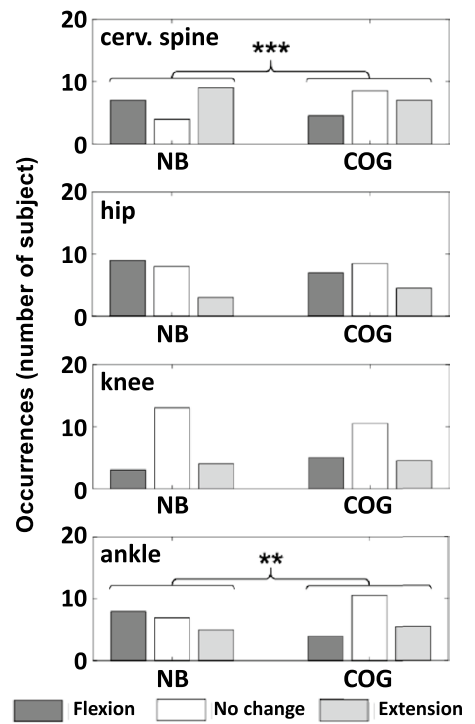

Fig. 7 a The cervical spine, hip, knee and ankle signal changes over a breathing cycle during natural breathing $(\mathrm{NB})$ and the cognitive task $(\mathrm{COG})$ in one subject (black line: mean value; grey shaded region: 95\% confidence interval); b motion distribution (flexion, no change and extension) measured in the 20 subjects for the cervical spine, hip, knee and ankle. Comparison between natural breathing (NB) and the cognitive task (COG) (proportions were compared with the exact test on the $2 \times 3$ corresponding contingency tables: $* * p<0.01$; $* * * p<0.001)$ 
Table 2 Change in the posturoventilatory interaction during the cognitive load condition

\begin{tabular}{|c|c|c|c|c|c|}
\hline$N=20$ & $\mathrm{CoP}$ & Cervical spine motion & Hip motion & Knee motion & Ankle motion \\
\hline \multicolumn{6}{|l|}{ TLA } \\
\hline No change & & +22.5 & +2.5 & -12.5 & +17.5 \\
\hline Flexion & & -12.5 & -10 & +10 & -20 \\
\hline Extension & & -10 & +7.5 & +2.5 & +2.5 \\
\hline$p$ & & 0.0024 & 0.2818 & 0.1384 & 0.0059 \\
\hline \multicolumn{6}{|l|}{ REm } \\
\hline$(\%)$ & $+7[-1 ;+12]$ & $-14[-35 ;-1]$ & $+1[-3 ;+10]$ & $0[-4 ;+3]$ & $+1[-3 ;+5]$ \\
\hline$p$ & 0.0696 & 0.0020 & 0.2943 & 0.8695 & 0.5217 \\
\hline
\end{tabular}

$T L A$ time locked averaging, $R E m$ : respiratory emergence, $C o P$ centre of pressure
Table 3 Posturo-ventilatory interaction at the cervical level during the cognitive load, eyes-closed and increased tidal volume conditions compared to natural breathing

\begin{tabular}{|c|c|c|c|c|}
\hline$N=20$ & NB & COG & $\mathrm{EC}$ & ITV \\
\hline \multicolumn{5}{|l|}{ Ventilation } \\
\hline $\begin{array}{l}\mathrm{BF} \\
\quad\left(\min ^{-1}\right)\end{array}$ & $\begin{array}{l}16.6 \\
{[13.3 ; 18.7]} \\
-\end{array}$ & $\begin{array}{l}18.6 \\
{[16.3 ; 19.4]} \\
0.0731\end{array}$ & $\begin{array}{l}16.3 \\
{[13.8 ; 18.1]} \\
0.9108\end{array}$ & $\begin{array}{l}13.5 \\
{[10.7 ; 18.5]} \\
0.5257\end{array}$ \\
\hline TI (s) & $\begin{array}{l}1.9 \\
{[1.5 ; 2.2]} \\
-\end{array}$ & $\begin{array}{l}1.8 \\
{[1.6 ; 1.9]} \\
0.2959\end{array}$ & $\begin{array}{l}2.0 \\
{[1.6 ; 2.3]} \\
0.5016\end{array}$ & $\begin{array}{l}2.2 \\
{[1.9 ; 2.9]} \\
0.1790\end{array}$ \\
\hline TE (s) & $\begin{array}{l}2.0 \\
{[1.7 ; 2.4]} \\
-\end{array}$ & $\begin{array}{l}1.7 \\
{[1.5 ; 1.9]} \\
\mathbf{0 . 0 2 2 8}\end{array}$ & $\begin{array}{l}1.9 \\
{[1.7 ; 2.3]} \\
0.3135\end{array}$ & $\begin{array}{l}2.3 \\
{[1.7 ; 3.4]} \\
0.1169\end{array}$ \\
\hline Amp. (L) & $\begin{array}{l}2.19 \\
{[1.35 ; 3.42]} \\
-\end{array}$ & $\begin{array}{l}2.01 \\
{[1.22 ; 2.78]} \\
0.3905\end{array}$ & $\begin{array}{l}2.40 \\
{[1.58 ; 2.81]} \\
0.8983\end{array}$ & $\begin{array}{l}9.10 \\
{[5.74 ; 10.93]} \\
\mathbf{8 . 2}^{*} \mathbf{1 0}^{-\mathbf{5}}\end{array}$ \\
\hline \multicolumn{5}{|l|}{$\begin{array}{l}\text { Cervical } \\
\text { spine }\end{array}$} \\
\hline Amp. $\left(^{\circ}\right)$ & $\begin{array}{l}1.14 \\
{[0.84 ; 1.60]} \\
-\end{array}$ & $\begin{array}{l}1.01 \\
{[0.62 ; 1.47]} \\
0.2180\end{array}$ & $\begin{array}{l}0.82 \\
{[0.66 ; 1.09]} \\
\mathbf{0 . 0 0 9 0}\end{array}$ & $\begin{array}{l}6.79 \\
{[4.19 ; 9.76]} \\
\mathbf{0 . 0 0 0 1}\end{array}$ \\
\hline $\operatorname{Rem}(\%)$ & $\begin{array}{l}17.2 \\
{[7.8 ; 37.2]} \\
-\end{array}$ & $\begin{array}{l}4.2 \\
{[1.8 ; 10.0]} \\
\mathbf{0 . 0 0 2 0}\end{array}$ & $\begin{array}{l}20.8 \\
{[8.0 ; 36.3]} \\
0.9702\end{array}$ & $\begin{array}{l}40.7 \\
{[19.1 ; 59.8]} \\
0.1169\end{array}$ \\
\hline \multicolumn{5}{|l|}{$\mathrm{CoP}$} \\
\hline $\begin{array}{l}\text { Amp. } \\
(\mathrm{mm})\end{array}$ & $\begin{array}{l}3.29 \\
{[2.04 ; 5.28]} \\
-\end{array}$ & $\begin{array}{l}5.74 \\
{[3.35 ;} \\
10.55] \\
\mathbf{0 . 0 0 7 2}\end{array}$ & $\begin{array}{l}3.15 \\
{[2.67 ; 3.63]} \\
0.4553\end{array}$ & $\begin{array}{l}5.57 \\
{[4.74 ; 7.45]} \\
\mathbf{0 . 0 0 1 0}\end{array}$ \\
\hline $\operatorname{Rem}(\%)$ & $\begin{array}{l}6.2 \\
{[3.8 ; 10.3]} \\
-\end{array}$ & $\begin{array}{l}12.9 \\
{[5.8 ; 20.7]} \\
0.0696\end{array}$ & $\begin{array}{l}9.3 \\
{[5.5 ; 14.4]} \\
0.1790\end{array}$ & $\begin{array}{l}18.3 \\
{[12.3 ; 25.1]} \\
\mathbf{0 . 0 0 0 4}\end{array}$ \\
\hline
\end{tabular}

Bold corresponds to significant $p<0.05$

The results are presented as the median [Q1; Q3] and the $p$ value obtained from Wilcoxon's test. The COG, EC and ITV conditions were compared to the NB condition

$B F$ breathing frequency, $T I$ inspiratory time, $T E$ expiratory time; Amp. Amplitude, REm respiratory emergence, $C o P$ centre of pressure, $N B$ natural breathing condition, $C O G$ cognitive condition, $E C$ eyes-closed condition, ITV increased tidal volume condition increase, though the difference was not significant, in the breathing frequency during the cognitive load, which was also previously reported (Grassmann et al. 2016). This modulation in the breathing pattern induced by a dual task is not surprising, as in addition to automatic commands, cortical commands transmitted from the primary cortex (Similowski et al. 1996), premotor cortex and supplementary motor area (Raux et al. 2007) control human respiration. To the best of our knowledge, however, our study is the first to demonstrate a specific modulation in the PV interaction under cognitive load. This result was shown in the subjects in our study by an increase in respiratory emergence close to statistical significance $(p=0.0696)$ and by significant changes in the TLA. This result indicates the central modulation of the PV interaction and suggests that postural control partly depends on central interactions between the cortical control of breathing and cognition in healthy humans. Therefore, as dual tasks are common in real-life settings, our results lead us to hypothesize that postural control may be less efficient in situations associated with a pathological adaptive increase in awake cortical respiratory drive, such as in healthy individuals during experimental dyspnoea (Raux et al. 2007) or in some patients with obstructive sleep apnoea syndrome (OSAS) (Launois et al. 2015), chronic obstructive pulmonary disease (COPD) (Nguyen et al. 2018) or hyperventilation syndrome (Dubois et al. 2016). In these settings, the pre-inspiratory potential observed in the motor cortex and the supplementary motor area during resting ventilation (Raux et al. 2007) has been associated with a perturbation of attentional resources (Sharman et al. 2014), which suggests that the balance between cognition, postural control and the control of breathing under cognitive load is impaired. This concept has been demonstrated in healthy subjects by a negative impact of experimental dyspnoea on both cognition and locomotion, as measured by the "timed up-and-go" test and its imagery version (Nierat et al. 2016). This concept has also been shown in patients with OSAS by a reduction in cognitive performance to maintain a balance performance similar to that of controls (Baillieul et al. 2018), but it remains to be specifically addressed. 


\section{Preservation of the cervical spine from breathing-related perturbations and cognitive load}

Our analysis at the joint level confirmed a significant reduction in the PV interaction at the cervical level and no change or increase at the other joints. Our results suggest that the PV interaction in humans cannot be modelled using a simple inverted pendulum model; rather, the model must take into account multiple degrees of freedom, as previously reported (Hodges et al. 2002; Kuznetsov and Riley 2012). Several joints (spine, hip, knee and ankle), each acting as a degree of freedom on the postural body chain, counteract the breathing-related postural perturbation and provide flexibility in central control (Hodges et al. 2002; Kuznetsov and Riley 2012) . In our study, we confirmed that this postural chain was altered under cognitive load. In addition, our study supports the hypothesis that the maintenance of stability of the neck is related to the protection of the cervical spine from ventilatory perturbations, as attested by the reduction in respiratory emergence at the cervical level. It has been previously reported that the breathing-related component of CoP displacements, i.e., the breathing-related postural perturbation, almost disappears during voluntary apnoea in healthy humans (Caron et al. 2004). Indeed, in healthy humans, during standing, even the breathing-related rhythmic perturbation is continuously counteracted, and this counteraction is not complete, which implies that natural breathing "normally perturbs" the balance along the multijoint postural chain (Kuznetsov and Riley 2012). Therefore, when a subject voluntarily holds his or her breath, the effect of the suppression of the breathing-related postural perturbation on the CoP displacements (Caron et al. 2004), as well as on the cervical spine motion (Hodges et al. 2002), may be linked to a "stabilization strategy". Similarly, in the subjects in our study, the reduction in the breathing-related perturbation, the unchanged amplitude of the motion of the cervical spine during cognitive load, and the increased amplitudes of postural sway and knee and ankle motion probably correspond to a "local stabilization strategy" of the cervical spine that may have limited the impairment of balance; however, we acknowledge this postulation remains to be addressed.

Actually, the stabilization of the neck may help maintain the head position and a horizontal gaze (Hasegawa et al. 2017). This compensatory adaptation may stem from the necessity to improve visual, vestibular and neck proprioceptive afferent feedback efficiency (Bove et al. 2009; Williams et al. 2017; Malmström et al. 2017) during a high-load cognitive task (Huxhold et al. 2006; Lacour et al. 2008), which is known to compromise balance by diverting attentional prefrontal resources (Mihara et al. 2008; Stelzel et al. 2018) that are primarily dedicated to the control of balance and anticipatory adjustments of the cervical curvature (Hamaoui and Alamini-Rodrigues 2017; Boulanger et al. 2017). Consequently, the stability of the cervical spine, which is known to play an important role in the maintenance of balance (see also Introduction section) (Gandelman-Marton et al. 2016; Hamaoui and Alamini-Rodrigues 2017), is probably crucial when cortical resources are challenged. Likewise, in COPD patients, who often recruit their respiratory neck muscles, pathologic breathing-related neck stabilization in dual-task settings may represent one of the physiopathological mechanisms of their specific postural dysfunction (Janssens et al. 2014). This hypothesis needs to be investigated in future studies.

\section{Methodological considerations and limitations}

We acknowledge that the instruction to subjects to focus their gaze on a landmark may have encouraged them to stabilize their neck. The instruction to stand barefoot on the force plate and focus their gaze on a landmark on the wall was used to minimize the variability of their posture and to avoid additional postural perturbations between subjects and between the NB and COG conditions. Therefore, the instruction's effect on balance was comparable in the reference NB and COG conditions. In addition, we acknowledge that this instruction may induce an additional cognitive load. Regardless of whether it induced an additional cognitive load, our results demonstrate that a higher cognitive load during the dual task was accompanied by a reduced respiratory postural perturbation at the neck joint level, no change in the neck motion, and increases in the COP displacement and lower joint motions. This strategy seems specific to a central modulation, as it was not observed during "non-cortical" postural perturbations, such as the EC or ITV conditions, while the breathing-related postural perturbation at the neck level remained unchanged.

In our study, the relatively small number of subjects, particularly that of subjects aged under 25 years $(n=3)$, limits our interpretation of the age effects present in our results. This factor remains to be addressed in future studies.

Balance in the standing position is a complex phenomenon that varies with postural alignment (Amabile et al. 2018), postural tone and metabolic cost (van Emmerik and van Wegen 2002; Houdijk et al. 2015). Therefore, some changes in postural sway are not associated with perturbations in balance. However, postural sway increases when balance tends to be compromised. This relation is the reason why we considered, by analogy, the amplitude of the motions of the cervical spine and other joints to be stability parameters of a given segment. We acknowledge that electromyography of the neck muscles can be useful; however, we are confident that the divergence between the cervical spine and other joints in terms of the breathing-related 
postural perturbation supports our "stabilization hypothesis" at the cervical level.

\section{Conclusion}

This study shows that the cervical spine is protected from the breathing-related postural perturbation during a cognitive dual task, while the postural perturbation occurs globally and at inferior joints. This result represents a cortical adaptation of the posturo-ventilatory interaction to stabilize the neck and possibly to limit the cognitive-induced postural perturbation. This adaptation may eventually become impaired in patients suffering from chronic respiratory disease. More generally, this adaptation supports the existence of a strong interaction between cognition, the control of breathing and postural control.

Author contributions LC, VA, BS and TS contributed substantially to the study design, data analysis and interpretation, and the writing of the manuscript. IR, MCN, PL and PR contributed substantially to the data analysis and interpretation, and the writing of the manuscript. All authors approved the final version of the manuscript and agreed to be accountable for all aspects of the work.

Funding This work was funded by the Chancellerie des Universités de Paris (Grant number: Legs Poix (LEG 1604)); ENS Cachan (Grant number: Ph.D. fellowship); Assistance Publique - Hôpitaux de Paris (Grant number: Grant "poste d'accueil APHP/Arts et Métiers" délégation à la Recherche Clinique et à l'Innovation (DRCI)); Paristech (Grant number: BiomeCAM chair)

\section{Compliance with ethical standards}

Conflict of interest The authors have no conflict of interest for this study.

\section{References}

Amabile C, Le Huec J-C, Skalli W (2018) Invariance of head-pelvis alignment and compensatory mechanisms for asymptomatic adults older than 49 years. Eur Spine J 27:458-466. https://doi. org/10.1007/s00586-016-4830-8

Attali V, Clavel L, Rouch P et al (2019) Compensation of respiratoryrelated postural perturbation is achieved by maintenance of headto-pelvis alignment in healthy humans. Front Physiol 10:441. https ://doi.org/10.3389/fphys.2019.00441

Baillieul S, Wuyam B, Pépin J-L et al (2018) Continuous positive airway pressure improves gait control in severe obstructive sleep apnoea: a prospective study. PLoS ONE 13:e0192442. https://doi. org/10.1371/journal.pone.0192442

Boulanger M, Giraudet G, Faubert J (2017) Interaction between the oculomotor and postural systems during a dual-task: compensatory reductions in head sway following visually-induced postural perturbations promote the production of accurate double-step saccades in standing human adults. PLoS ONE 12:e0173678. https:// doi.org/10.1371/journal.pone.0173678
Bove M, Fenoggio C, Tacchino A et al (2009) Interaction between vision and neck proprioception in the control of stance. Neuroscience 164:1601-1608. https://doi.org/10.1016/j.neuroscien ce. 2009.09 .053

Cala SJ, Kenyon CM, Ferrigno G et al (1996) Chest wall and lung volume estimation by optical reflectance motion analysis. J Appl Physiol 81:2680-2689

Caron O, Fontanari P, Cremieux J, Joulia F (2004) Effects of ventilation on body sway during human standing. Neurosci Lett 366:6-9. https://doi.org/10.1016/j.neulet.2004.04.085

Dally JFH (1908) An inquiry into the physiological mechanism of respiration with especial reference to the movements of the vertebral column and diaphragm. Proc R Soc 80:93-114

David P, Laval D, Terrien J, Petitjean M (2012) Postural control and ventilatory drive during voluntary hyperventilation and carbon dioxide rebreathing. Eur J Appl Physiol 112:145-154. https://doi. org/10.1007/s00421-011-1954-8

Dubois M, Chenivesse C, Raux M et al (2016) Neurophysiological evidence for a cortical contribution to the wakefulness-related drive to breathe explaining hypocapnia-resistant ventilation in humans. J Neurosci 36:10673-10682. https://doi.org/10.1523/ JNEUROSCI.2376-16.2016

Dubousset J (1994) Three-dimensional analysis of scoliotic deformity. In: Weinstein SL (ed) Pediatric spine: principles and practices. Raven Press ltd, NY, pp 479-496

Gandelman-Marton R, Arlazoroff A, Dvir Z (2016) Postural stability in patients with different types of head and neck trauma in comparison to healthy subjects. Brain Inj 30:1612-1616. https://doi. org/10.1080/02699052.2016.1199904

Grassmann M, Vlemincx E, von Leupoldt A et al (2016) Respiratory changes in response to cognitive load: a systematic review. Neural Plast 2016:1-16. https://doi.org/10.1155/2016/8146809

Gurfinkel VS, Kots YM, Paltsev EI, Feldman AG (1971) The compensation of respiratory disturbances of the erect posture of man as an example of the organization of interarticular interaction. In: Gelfand IM, S GV, V FS, L TM (eds) Models of the structuralfunctional organization of certain biological systems, Cambridge, Massachusetts

Hagio K, Obata H, Nakazawa K (2018) Effects of breathing movement on the reduction of postural sway during postural-cognitive dual tasking. PLoS ONE 13:e0197385. https://doi.org/10.1371/journ al.pone. 0197385

Hamaoui A, Alamini-Rodrigues C (2017) Influence of cervical spine mobility on the focal and postural components of the sit-to-stand task. Front Hum Neurosci 11:129. https://doi.org/10.3389/fnhum .2017 .00129

Hamaoui A, Gonneau E, Le Bozec S (2010) Respiratory disturbance to posture varies according to the respiratory mode. Neurosci Lett 475:141-144. https://doi.org/10.1016/j.neulet.2010.03.064

Hasegawa K, Okamoto M, Hatsushikano S et al (2017) Standing sagittal alignment of the whole axial skeleton with reference to the gravity line in humans. J Anat 230:619-630. https://doi. org/10.1111/joa.12586

Hodges PW, Gandevia SC, Richardson CA (1997) Contractions of specific abdominal muscles in postural tasks are affected by respiratory maneuvers. J Appl Physiol 83:753-760

Hodges PW, Gurfinkel VS, Brumagne S et al (2002) Coexistence of stability and mobility in postural control: evidence from postural compensation for respiration. Exp Brain Res 144:293-302. https ://doi.org/10.1007/s00221-002-1040-x

Hodges PW, Sapsford R, Pengel LHM (2007) Postural and respiratory functions of the pelvic floor muscles. Neurourol Urodyn 26:362371. https://doi.org/10.1002/nau.20232

Houdijk H, Brown SE, van Dieën JH (2015) Relation between postural sway magnitude and metabolic energy cost during upright 
standing on a compliant surface. J Appl Physiol 119:696-703. https://doi.org/10.1152/japplphysiol.00907.2014

Huxhold O, Li S-C, Schmiedek F, Lindenberger U (2006) Dual-tasking postural control: aging and the effects of cognitive demand in conjunction with focus of attention. Brain Res Bull 69:294-305. https://doi.org/10.1016/j.brainresbull.2006.01.002

Jahn K, Deutschländer A, Stephan T et al (2004) Brain activation patterns during imagined stance and locomotion in functional magnetic resonance imaging. Neuroimage 22:1722-1731. https://doi. org/10.1016/j.neuroimage.2004.05.017

Janssens L, Brumagne S, McConnell AK et al (2014) Impaired postural control reduces sit-to-stand-to-sit performance in individuals with chronic obstructive pulmonary disease. PLoS ONE 9:1-5. https:// doi.org/10.1371/journal.pone.0088247

Kantor E, Poupard L, Le Bozec S, Bouisset S (2001) Does body stability depend on postural chain mobility or stability area? Neurosci Lett 308:128-132. https://doi.org/10.1016/S0304-3940(01)01986 $-3$

Kuznetsov NA, Riley MA (2012) Effects of breathing on multijoint control of center of mass position during upright stance. J Mot Behav 44:241-253. https://doi.org/10.1080/00222895.2012.68889 4

Lacour M, Bernard-Demanze L, Dumitrescu M (2008) Posture control, aging, and attention resources: models and posture-analysis methods. Neurophysiol Clin Neurophysiol 38:411-421. https:// doi.org/10.1016/j.neucli.2008.09.005

Launois C, Attali V, Georges M et al (2015) Cortical drive to breathe during wakefulness in patients with obstructive sleep apnea syndrome. Sleep 38:1743-1749. https://doi.org/10.5665/sleep.5156

Mador MJ, Tobin MJ (1991) Effect of alterations in mental activity on the breathing pattern in healthy subjects. Am Rev Respir Dis 144:481-487. https://doi.org/10.1164/ajrccm/144.3_Pt_1.481

Malmström E-M, Fransson P-A, Jaxmar Bruinen T et al (2017) Disturbed cervical proprioception affects perception of spatial orientation while in motion. Exp Brain Res 235:2755-2766. https://doi. org/10.1007/s00221-017-4993-5

Manor BD, Hu K, Peng CK et al (2012) Posturo-respiratory synchronization: effects of aging and stroke. Gait Posture 36:254-259. https ://doi.org/10.1016/j.gaitpost.2012.03.002

Mihara M, Miyai I, Hatakenaka M et al (2008) Role of the prefrontal cortex in human balance control. Neuroimage 43:329-336. https ://doi.org/10.1016/j.neuroimage.2008.07.029

Nguyen DAT, Boswell-Ruys CL, McBain RA et al (2018) Inspiratory pre-motor potentials during quiet breathing in ageing and chronic obstructive pulmonary disease. J Physiol 596:6173-6189. https:// doi.org/10.1113/JP275764

Nierat M-C, Demiri S, Dupuis-Lozeron E et al (2016) When breathing interferes with cognition: experimental inspiratory loading alters timed up-and-go test in normal humans. PLoS ONE 11:e0151625. https://doi.org/10.1371/journal.pone.0151625
Park E, Schöner G, Scholz JP (2012) Functional synergies underlying control of upright posture during changes in head orientation. PLoS ONE 7:e41583. https://doi.org/10.1371/journal.pone.00415 83

Perry SF, Carrier DR (2006) The coupled evolution of breathing and locomotion as a game of leapfrog. Physiol Biochem Zool 79:997999. https://doi.org/10.1086/507657

Quek J, Treleaven J, Clark RA, Brauer SG (2018) An exploratory study examining factors underpinning postural instability in older adults with idiopathic neck pain. Gait Posture 60:93-98. https://doi. org/10.1016/j.gaitpost.2017.11.016

Raux M, Straus C, Redolfi S et al (2007) Electroencephalographic evidence for pre-motor cortex activation during inspiratory loading in humans. J Physiol 5782:569-578. https://doi.org/10.1113/jphys iol.2006.120246

Sharman M, Gallea C, Lehongre K et al (2014) The cerebral cost of breathing: an fMRI case-study in congenital central hypoventilation syndrome. PLoS ONE 9:e107850. https://doi.org/10.1371/ journal.pone.0107850

Similowski T, Straus C, Coïc L, Derenne JP (1996) Facilitation-independent response of the diaphragm to cortical magnetic stimulation. Am J Respir Crit Care Med 154:1771-1777. https://doi. org/10.1164/ajrccm.154.6.8970369

Stelzel C, Bohle H, Schauenburg G et al (2018) Contribution of the lateral prefrontal cortex to cognitive-postural multitasking. Front Psychol 9:1075. https://doi.org/10.3389/fpsyg.2018.01075

Talasz H, Kremser C, Kofler M et al (2011) Phase-locked parallel movement of diaphragm and pelvic floor during breathing and coughing-a dynamic MRI investigation in healthy females. Int Urogynecol J 22:61-68. https://doi.org/10.1007/s0019 2-010-1240-z

Taube W, Gruber M, Gollhofer A (2008) Spinal and supraspinal adaptations associated with balance training and their functional relevance. Acta Physiol 193:101-116. https://doi.org/10.111 1/j.1748-1716.2008.01850.x

van Emmerik REA, van Wegen EEH (2002) On the functional aspects of variability in postural control. Exerc Sport Sci Rev 30:177-183

Vital JM, Senegas J (1986) Anatomical bases of the study of the constraints to which the cervical spine is subject in the sagittal plane. A study of the center of gravity of the head. Surg Radiol Anat 8:169-173

Williams K, Tarmizi A, Treleaven J (2017) Use of neck torsion as a specific test of neck related postural instability. Musculoskelet Sci Pract 29:115-119. https://doi.org/10.1016/j.msksp.2017.03.012

Publisher's Note Springer Nature remains neutral with regard to jurisdictional claims in published maps and institutional affiliations. 